\title{
Italian real life experience with brentuximab vedotin: results of a large observational study on 234 relapsed/refractory Hodgkin's lymphoma
}

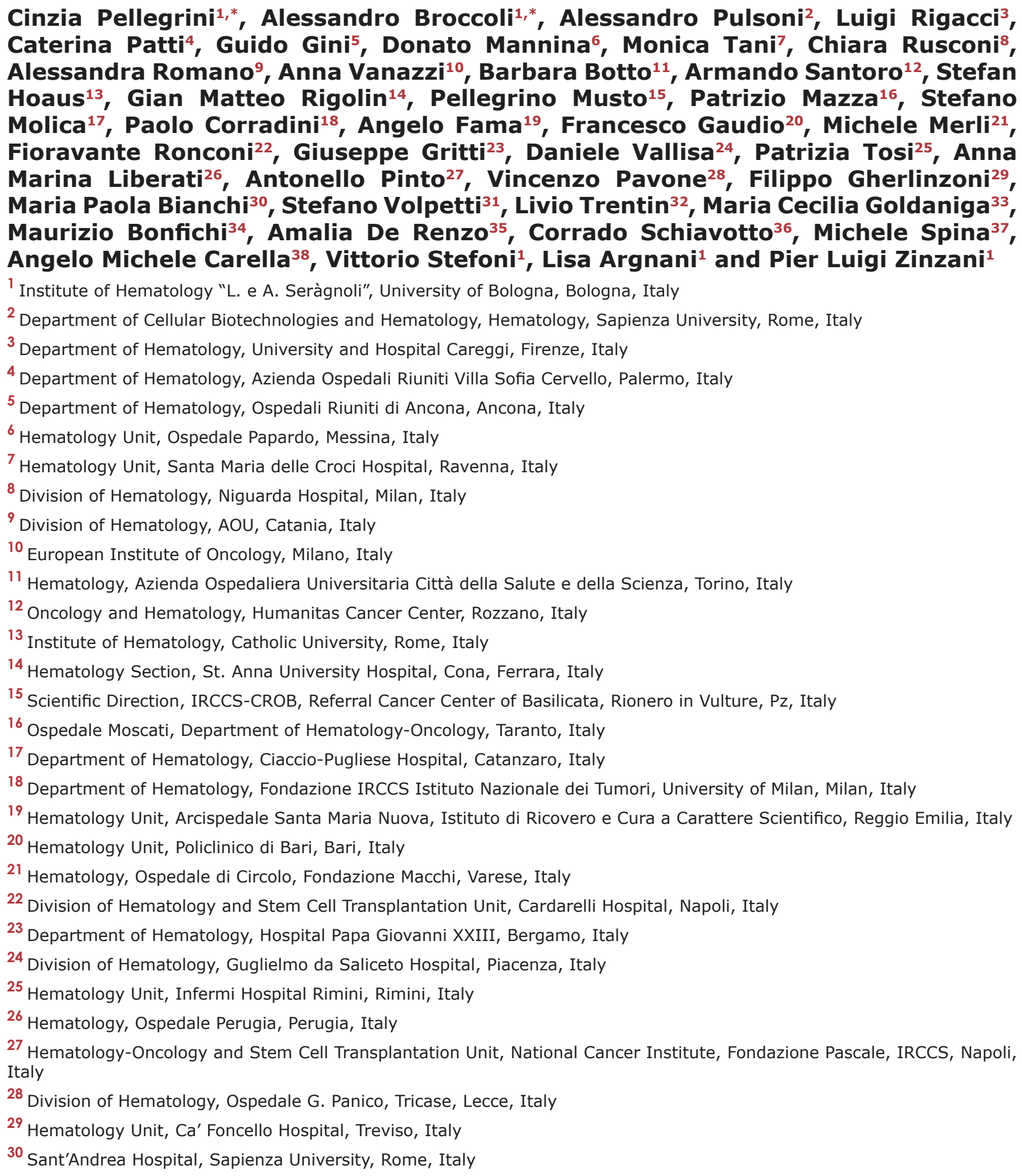


${ }^{31}$ Department of Hematology, DISM, Azienda Sanitaria Universitaria Integrata, Udine, Italy

32 Department of Medicine, Hematology and Clinical Immunology Unit, University of Padua, Padua, Italy

${ }^{33}$ Onco-Hematology Unit, Fondazione Ca' Granda IRCCS Ospedale Maggiore Policlinico, Milan, Italy

${ }^{34}$ Hematology, IRCCS Policlinico San Matteo, Pavia, Italy

${ }^{35}$ Hematology, AOU Federico II Napoli, Napoli, Italy

${ }^{36}$ Hematology, San Bortolo Hospital, Vicenza, Italy

${ }^{37}$ Division of Medical Oncology A, National Cancer Institute, Aviano, Italy

${ }^{38}$ Division of Hematology 1, IRCCS A.O.U. San Martino IST, Genova, Italy

"These authors have contributed equally to this work

Correspondence to: Pier Luigi Zinzani, email: pierluigi.zinzani@unibo.it

Keywords: brentuximab vedotin, long-term response, real life, Hodgkin's lymphoma, stem cell transplantation

Received: April 04, 2017

Accepted: May 08, 2017

Published: May 23, 2017

Copyright: Pellegrini et al. This is an open-access article distributed under the terms of the Creative Commons Attribution License 3.0 (CC BY 3.0), which permits unrestricted use, distribution, and reproduction in any medium, provided the original author and source are credited.

\section{ABSTRACT}

A large Italian multicenter observational retrospective study was conducted on the use of brentuximab vedotin (BV) for patients with relapsed Hodgkin's lymphoma (HL) to check if clinical trial results are confirmed even in a real life context. 234 CD30+ HL patients were enrolled. Best response was observed after a median of 4 cycles in 140 patients (59.8\%): 74 (31.6\%) patients obtained a complete response (CR) and $66(28.2 \%)$ achieved a partial response (PR); overall response rate at the end of the treatment was $48.3 \%$ ( 62 CR and 51 PR). The best response rate was higher in the elderly subset: 14 (50\%) CR and 5 (17.8\%) PR. Disease free survival was $26.3 \%$ at 3 years and progression free survival $31.9 \%$ at 4.5 years. Duration of response did not differ for who achieved at least PR and then either did or did not undergo consolidative transplant. Overall, the treatment was well tolerated and no death has been linked to BV-induced toxicity.

Our report confirms activity in elderly patients, duration of response unrelated to the consolidation with transplant procedure, the relevance of the CR status at first restaging, and the role of $\mathrm{BV}$ as a bridge to transplant for chemorefractory patients.

\section{INTRODUCTION}

Conventional chemotherapy (with radiotherapy in case of localized disease) has made Hodgkin's lymphoma (HL) a curable disease for most of the patients. Salvage chemotherapy followed by high dose therapy and autologous stem cell transplantation (ASCT) represents the treatment of choice for relapsed/refractory $(\mathrm{R} / \mathrm{R})$ patients, since this therapeutic strategy can provide long-term disease control in approximately $50 \%$ of $\mathrm{R} / \mathrm{R}$ patients.[1-6] For patients with HL who relapse after ASCT, conventional salvage chemotherapies are often unsatisfactory. The outcome of this subset of patients is rather dismal with a median overall survival (OS) of 2 years. [7, 8] Relapsed disease after ASCT is considered incurable, unless allogeneic transplant (alloSCT) is applied. However, very few patients can achieve this goal, since refractory disease often hampers the benefits of this procedure.
CD30 is a transmembrane-receptor protein expressed on activated $\mathrm{B}$ and $\mathrm{T}$ lymphocytes and on the surface of malignant Hodgkin Reed-Sternberg cells. Through CD30-CD30-ligand interaction, eosinophils and mast cells may stimulate those malignant cells, promoting their survival.[9] Brentuximab vedotin (BV) is a chimeric anti-CD30 antibody conjugate via a protease-cleavable linker to a microtubule-disrupting agent, monomethyl auristatin E. After binding to cell-surface CD30, that agent is internalized, traffics to the lysosome and is released to disrupt microtubules, inducing cell-cycle arrest and apoptosis.[10] Several studies have shown the efficacy of $\mathrm{BV}$ in patients with $\mathrm{HL}$ starting from the pivotal phase II study on patients with R/R disease after ASCT, reporting a $75 \%$ of objective response rate (ORR) with $34 \%$ of complete response (CR).[11] This high response rate is important not only for heavily pretreated patients with a poor prognosis, but also for first-line $\mathrm{R} / \mathrm{R}$ patients, because a CR status before the transplant procedure is one of the stronger predictors for long-term survival.[12-18] BV 
can represent an optimal therapeutic option as a bridge to ASCT or alloSCT in patients who showed a suboptimal response after conventional salvage treatment.[15, 19, 20] Recent updates of the two pivotal studies have shown that $\mathrm{BV}$ can induce long lasting $\mathrm{CR}$ in $\mathrm{HL}$ pretreated cases either without additional consolidation therapies suggesting that BV may lead to a long disease control in some patients.[21, 22]

After accelerated approval by US Food and Drug Administration, eligible patients in Italy were granted early access through a Named Patient Programme (NPP). After the closure of NPP, between 2012 and 2014 BV was available in Italy for patients with relapsed HL, based on a local disposition of the Italian Drug Agency issued according to a national law (Law 648/96: "medicinal products that are provided free of charge on the national health service"): a boundary zone in the passage from clinical trials to marketing and free use phases where patients can be treated in any case.

On the basis of our previous explorative study, a large Italian observational retrospective study was conducted on the use of BV in the everyday clinical practice to check if clinical trial results are confirmed even in a real life context. [23]

\section{RESULTS}

Of the estimated 238 patients who received BV under the Law 648/96, 4 (2\%) refused to participate in this observational study. Characteristics of the 234 patients are summarized in Table 1. The median age at BV was 35.4 years (range, 18-79 years) with 28 (12.0\%) elderly patients (age $\geq 60$ years); 129 were males and 105 were females. One-hundred-sixteen $(49.6 \%)$ had systemic symptoms at baseline.

The median number of prior treatment regimens was 3 (range, 1-6) including high dose chemotherapy and ASCT (in 163, 69.6\% of the patients). Ninety-eight patients $(41.9 \%)$ had received prior radiation therapy. For each patient the status after both frontline therapy and most recent therapy was collected: 119 (50.8\%) patients had disease that was refractory to frontline therapy and 164 patients $(70.1 \%)$ had disease that was refractory to last therapy before $\mathrm{BV}$.

\section{Response to treatment}

Best response was observed after a median of 4 cycles in $140(59.8 \%)$ patients: $74(31.6 \%)$ obtained a CR and 66 (28.2\%) achieved a partial response (PR). ORR at the end of the treatment was $48.3 \%$ (113 patients) represented by $62(26.5 \%) \mathrm{CR}$ and 51 (21.7\%) PR; among the remaining patients, 36 had stable disease (SD), and 85 patients showed progression of disease (PD), respectively.
The best response rate was higher $(\mathrm{p}<0.05)$ in the elderly subset ( $>60$ years): 14 (50\%) CR and 5 (17.8\%) PR. In the elderly setting the ORR was $46.4 \%$ (13 patients) represented by 11 (39.3\%) CR and 2 (7.1\%) PR.

We performed analyses to report outcomes of patients who underwent stem cell transplant compared to those who did not. Patients who had a prior ASCT were further considered with two criteria: first we calculated overall response rate in patients who underwent ASCT any time before brentuximab then in the ones who had ASCT immediately before brentuximab. In patients who had ASCT any time before brentuximab $(n=163)$ ORR after BV was $53.9 \%$ and complete response rate $29.4 \%$. In patients who had ASCT immediately before brentuximab $(n=89)$ ORR after BV was $75.3 \%$ and CR rate $29.2 \%$. In patients who did not undergo ASCT before brentuximab $(n=71)$ ORR after BV was $50.7 \%$ and CR rate $25.4 \%$.

Twelve patients who were in CR after 4 cycles (the first evaluation as per schedule) relapsed during subsequent BV courses; fifteen patients who were in PR at the first restaging converted to $\mathrm{CR}$ status after further four BV infusions. All patients but one who were in SD or $\mathrm{PD}$ at first restaging did not improve their status at the end of therapy. Globally, the median number of cycles administered was 6 (range 1-16).

At a median follow up of 18 months OS was $59.8 \%$ at 55 months (Figure 1), median has not reached yet. Global progression free survival (PFS) at 55 months was $31.9 \%$, the median was achieved at 11 months (Figure 2). Global disease free survival (DFS) was $26.3 \%$ at 29 months (Figure 3); 14 out of 62 (22.6\%) CR patients relapsed, whereas 48 patients are in continuous CR (CCR) with median duration of response (DoR) of 23.8 months.

Among the responder patients (CR + PR), 38 patients had a consolidation with transplant (16 ASCT and 22 alloSCT) next to BV treatment; the estimated PFS at 36 months as a function of transplant consolidation did not show statistically significant difference between patients with consolidation $(43.7 \%$, median reached at 17.6 months) vs. patients who did not undergo consolidation (30.1, median reached at 9.0 months) (Figure 4).

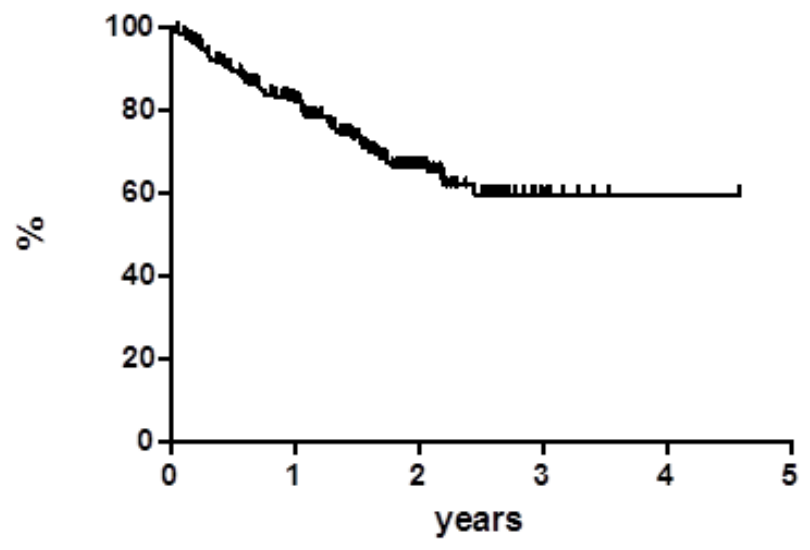

Figure 1: Overall survival. 
Table 1: Patient demographics and characteristics at baseline

\begin{tabular}{|l|c|c|}
\hline & Total population & Elderly ( $\geq \mathbf{6 0})$ \\
\hline Patients, $N$ & 234 & 28 \\
\hline Median age, years (range) & $35.4(18.0-79.0)$ & $66.5(60.2-78.6)$ \\
\hline Median time from diagnosis-BV*, years (range) & $2.3(1.0-33)$ & $2.9(1.0-19.5)$ \\
\hline Male, $N(\%)$ & $129(55.1)$ & $17(60.7)$ \\
\hline Stage, $N(\%)$ & $99(42.3)$ & $11(39.3)$ \\
- I/II & $48(20.5)$ & $6(21.4)$ \\
- III & $87(37.2)$ & $11(39.3)$ \\
- IV & & $7(25.0)$ \\
\hline ECOG performance status, $N(\%)$ & $26(60.5)$ & $16(57.1)$ \\
-0 & $17(39.5)$ & $5(17.8)$ \\
\hline-1 & - & $1(3.5)$ \\
- 2 & $12(5.1)$ & $2(7.1)$ \\
\hline Bulky disease, $N(\%)$ & $15(6.4)$ & $10(35.7)$ \\
\hline Bone marrow involvement, $N(\%)$ & $116(49.6)$ & $16(57.1)$ \\
\hline Systemic symptoms, $N(\%)$ & $164(70.1)$ & $9(32.1)$ \\
\hline - Refractory to most recent therapy, $N(\%)$ & $119(50.8)$ & $2(1-6)$ \\
\hline - Refractory to first line therapy, $N(\%)$ & $3(1-6)$ & $11(39.3)$ \\
\hline Median number of previous therapies (range) & $163(69.8)$ & $7(25.0)$ \\
\hline Prior autologous stem cell transplant, $N(\%)$ & $98(41.9)$ & \\
\hline Prior radiotherapy, $N(\%)$ & & \\
\hline
\end{tabular}

*BV: brentuximab vedotin; ${ }^{\dagger}$ ECOG: Eastern Cooperative Oncology Group.

Currently, there are 18/30 long term responder patients (LTR) still in CCR: 7 with consolidative transplant and 11 without any consolidative procedure. At the latest followup, $172(73.5 \%)$ patients were alive and 62 deceased (47 due to lymphoma, 14 for other reasons, and 1 for acute myeloid leukemia [AML] at 2 months from the end of the treatment).

\section{Safety}

All patients who received at least one BV infusion were included in the safety analysis. In general, the treatment was well tolerated and the toxicity profile was very similar to the previously published data. One-

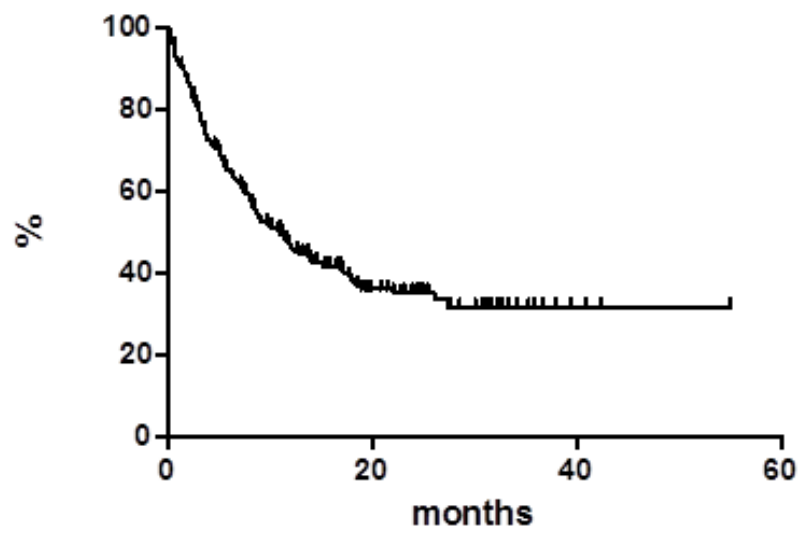

Figure 2: Progression free survival. hundred-five (44.8\%) patients had an early treatment discontinuation: 10 due to extrahematologic toxicity, 38 for bridge to transplant, and 57 due to PD, with 3 deaths. Globally only $15(6.4 \%)$ patients performed 16 cycles.

Sixty-nine $(29.5 \%)$ patients had at least one toxicity. Among hematologic side effects, grade 3/4 adverse events (AE) were reported in 9 patients: neutropenia ( $n$ $=7)$, thrombocytopenia $(n=1)$, and pancytopenia $(n=$ 1) all related to BV. Grade 3/4 extrahematologic toxicity was observed in 22 patients: 1 pancreatitis (related), 2 respiratory failures (related), 1 AML, 1 acute respiratory distress syndrome and 17 peripheral sensory neuropathies (related). Resolution or improvement of peripheral neuropathy was observed in $90 \%$ of patients with a median time to resolution or improvement of 12 weeks.

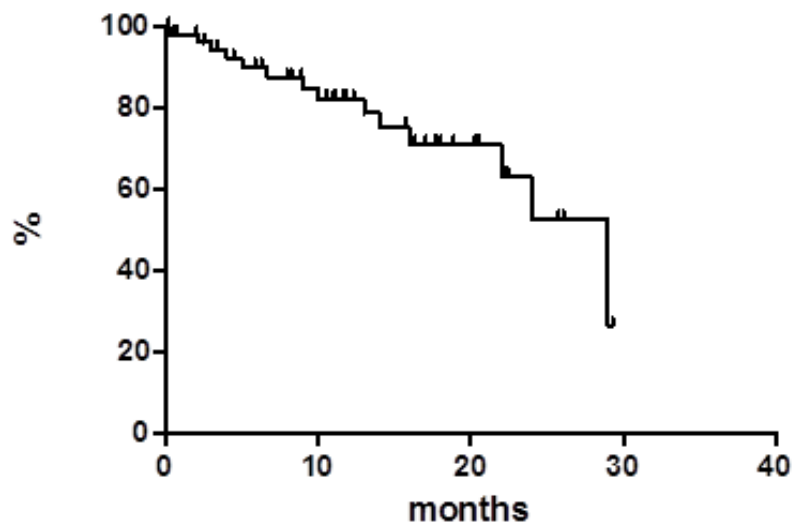

Figure 3: Disease free survival. 


\section{DISCUSSION}

This retrospective multicenter Italian study on 234 patients with $\mathrm{R} / \mathrm{R}$ HL represents one of the two larger reports ever published together with the French experience.[18] To note, in the French report were included also 37/240 (15.4\%) patients who had alloSCT prior to BV. Our results are in accordance to the pivotal phase II study and to the other experiences both experimental and observational with an ORR of $59.8 \%$ and a $\mathrm{CR}$ rate of $31.6 \%$ in terms of best response, i.e. achieved any time during treatment.[11, 12, 14, 16-18, 23, 24]

Previous published data refer to a NPP. There is a boundary zone in the passage from phase III to phase IV trials, i.e. from experimental to marketing and free use phases: in this zone patients can be treated with unapproved drugs by means of NPP, compassionate and off-label use and, in Italy as in the present report, under request according to Law 648/96. The main difference between a NPP and Law 648/96 lies in inclusion/exclusion criteria: under Law 648/96 physicians use the drug in a wider spectrum of patients with varied underlying diseases and a broad range of concomitant medications. Thus, we added additional useful information about the management of BV in the real life.

No selection bias at all, as BV was prescribed as per clinical indication and Centers and patients were consecutively enrolled.

Some interesting considerations about the role of $\mathrm{BV}$ in everyday clinical practice can be extrapolated. The best response rate was higher in the elderly setting ( 28 patients with an age $>60$ years) with an ORR of $67.8 \%$ and a CR rate of 50\% (all in CCR at the latest followup) confirming the high activity of $\mathrm{BV}$ in this patients subset at the same number of cycles performed [24, 25]. The comparison with the report summing up BV clinical trials results between 2006 and 2012 shows that in our series the clinical response is superior in terms of CR, ORR, and CCR.[13, 24] The patients who had a prior ASCT (suggesting chemo-sensitivity) had a better ORR than those who had not (suggesting chemo-resistance and primary refractory disease), while CR rates are comparable. This observation provides additional data on the activity of $\mathrm{BV}$ in refractory patients.

To be in CR after 4 cycles is confirmed very important for classifying the patient as a real good responder; at the same time, the right number of cycles to be performed for evaluating the potential consolidation with transplant (in the major part allogeneic transplant) or the continuation with $\mathrm{BV}$ until the cycle 16 remains an open issue, mainly because in case of CR the choice between the two options is at the physician discretion. Recently, Chen et al., updating on the pivotal phase II study, reported that the 5-year PFS was $67 \%$ in CR patients submitted to allotransplant next to $\mathrm{BV}$ versus
$48 \%$ in patients who continued treatment after achieving $\mathrm{CR}$ to $\mathrm{BV}$ at the first restaging without any statistically significant difference. $[11,22]$ Moreover, in this update the authors reported that $9 \%$ of the enrolled study population has achieved a long-term remission (exceeding 5 years) without any further anti-lymphoma therapy after treatment with single agent BV. In our study, the estimated PFS at 3 years did not show statistically significant difference between patients who underwent consolidation (43.7\%) vs. patients who did not (30.1\%). At the time of writing, 48 (20.5\% of all study population) patients were in CCR with a median duration of response of 29 months. Thus, also in the real life experience these survival outcomes showed that a substantial subset of patients among $R / R$ $\mathrm{HL}$ obtained $\mathrm{CR}$ to single agent $\mathrm{BV}$ with a long-term disease control. Also the length of the follow up denotes the potential cure in some patients despite their lymphoma history.

An important question remains unanswered: among the CR patients, which may benefit from the transplant consolidation? In our series there were 30 LTR patients and 18 are still in CCR, 7 with consolidative transplant next to $\mathrm{BV}$ and 11 without any consolidative procedure: among these two subsets it was impossible to extrapolate any significant clinical characteristic to identify which is the best profile to move to a transplant procedure. Our study indicated that for patients who obtained a SD or PD after 4 cycles the potential conversion rate to PR or $\mathrm{CR}$ with further BV administrations is close to zero: only one patients out of $84(1.2 \%)$ achieved a CR after a SD. The final message is that when patients show SD or PD at first restaging, they have to be shifted rapidly to another treatment. On the other hand, for patients who achieved PR after first restaging it could be important to continue the treatment: in our series 15/66 (22.7\%) patients showed a conversion from PR to $\mathrm{CR}$ status, suggesting they continued to benefit from therapy.

Another interesting issue is the use of $\mathrm{BV}$ as a bridge to ASCT for chemorefractory patients: literature data in this topic show great promise.[24, 26, 27] In our study 16 patients were treated with BV before ASCT due to chemorefractoriness and were intended to proceed to ASCT. Among them, 8 patients had a response and finally 8 patients underwent ASCT. The toxicity profile was closely similar to the previously published data; no death

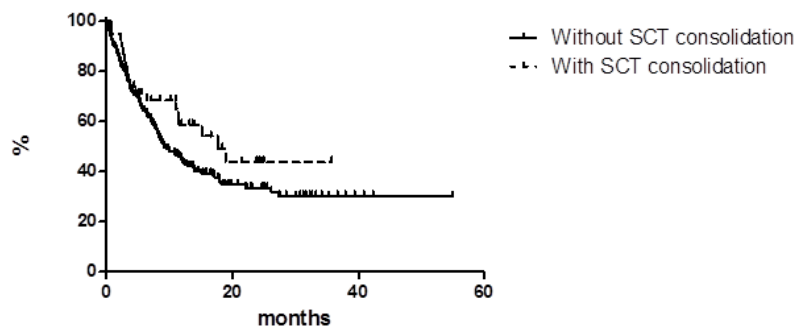

Figure 4: Progression free survival in patients with and without stem cell transplant (SCT) consolidation. 
has been linked to BV-induced toxicity.

In conclusion, the results of this large retrospective study on $234 \mathrm{R} / \mathrm{R}$ HL in the real world support the effectiveness of $\mathrm{BV}$ with a manageable toxicity as previously reported also in clinical trials; in particular, our report confirms activity also in elderly patients, duration of the clinical response unrelated to the consolidation with transplant procedure, the relevance of the CR status at first restaging for the quality of the final response, and the role of BV as a bridge to ASCT for chemorefractory patients.

\section{MATERIALS AND METHODS}

An observational retrospective study was conducted on patients with $\mathrm{R} / \mathrm{R}$ HL treated with $\mathrm{BV}$ in 40 Italian centers outside clinical trials.[28] The study was approved by our institutional board (Azienda Ospedaliera di Bologna, Policlinico S.Orsola-Malpighi, coordinating center) and by all involved Ethical Committees and registered in the Italian Registry of Observational Studies. All participants gave written informed consent in accordance with the Declaration of Helsinki. A shared database was used after the approval of all the coinvestigators and variables were strictly defined to avoid bias in reporting data. We obtained a special permission (for scientific purpose) from our Ethical Committee to collect even data of patients who were deceased or lost to follow up.

From November 2012 to July 2014, a total of 234 patients with $\mathrm{R} / \mathrm{R}$ HL were treated with $\mathrm{BV}$ according to the Italian law 648/96. All patients had histologically confirmed $\mathrm{CD} 30+$ disease; subjects were relapsed after prior ASCT or relapsed after at least two lines of chemotherapy if not eligible for ASCT due to insufficient stem cell collection or chemorefractory disease.

Patients received a 30-minute infusion of BV at the dose of $1.8 \mathrm{mg} / \mathrm{kg}$ of body weight every 3 weeks for a maximum of 16 cycles. Dose reduction to $1.2 \mathrm{mg} / \mathrm{kg}$ was recommended in case of grade 3 toxicity. The treatment was interrupted in case of grade 4 toxicity.

The primary endpoint of the study was the best response achieved any time during BV therapy; secondary endpoints were ORR at the end of the treatment, DoR, OS, PFS, DFS, and the incidence and severity of any AE occurring during treatment. Effectiveness was also evaluated through the occurrence of LTR patients, defined as patients who have response (CR or PR) duration $\geq 12$ months. Response was assessed by PET/CT scan after cycle 4, 8, 12 and at drug discontinuation using the International Working Group revised response criteria for malignant lymphoma.[29] Safety and tolerability were evaluated by recording incidence, severity, and type of any $\mathrm{AE}$ according to the National Cancer Institute Common Terminology Criteria for AEs v4.0.

ORR was defined as the sum of $C R$ and $P R$ rates at the end of $\mathrm{BV}$ treatment and before any type of consolidation. OS was defined as the time from initiation of therapy to death from any cause and was censored at the date of last available follow up. PFS was measured from initiation of therapy to progression, relapse, or death from any cause and was censored at the date of last available follow up. DFS was calculated for CR patients from the first documentation of response to the date of relapse or death due to lymphoma or acute toxicity of treatment. DoR was calculated from the first objective tumor response (CR or PR) to first documentation of progression or death.[29]

Demographics and patients' characteristics as well AEs were summarized by descriptive statistics. Survival functions were estimated by using the Kaplan-Meier method and were compared using log-rank test. Statistical analyses were performed with Stata 11 (StataCorp LP, TX) and $\mathrm{p}$ values were set at 0.05 .

\section{Abbreviations}

AE, adverse event; alloSCT, allogeneic stem cell transplant; ASCT, autologous stem cell transplant; BV, brentuximab vedotin; CCR, continuous complete response; CR, complete response; DFS, disease free survival; DoR, duration of response; HL, Hodgkin's lymphoma; LTR, long term responder; ORR, objective response rate; OS, overall survival; $\mathrm{PD}$, progression of disease; $\mathrm{PR}$, partial response; PFS, progression free survival; R/R, relapsed/ refractory; SD, stable disease.

\section{Author contributions}

Conception and design: C. Pellegrini, A. Broccoli, L. Argnani, P.L. Zinzani Acquisition of data: All authors Writing of the manuscript: C. Pellegrini, A. Broccoli, L. Argnani, P.L. Zinzani Administrative, technical, or material support: L. Argnani, P.L. Zinzani Study supervision: L. Argnani, P.L. Zinzani. Review and/or revision of the manuscript: All authors

Final approval of the manuscript: All authors.

\section{CONFLICTS OF INTEREST}

No potential conflicts of interest were disclosed.

\section{REFERENCES}

1. Arai S, Fanale M, DeVos S, Engert A, Illidge T, Borchmann P, Younes A, Morschhauser F, McMillan A, Horning SJ. Defining a Hodgkin lymphoma population for novel therapeutics after relapse from autologous hematopoietic cell transplant. Leuk Lymphoma. 2013; 54:2531-33.

2. Josting A, Rudolph C, Mapara M, Glossmann JP, Sieniawski M, Sieber M, Kirchner HH, Dörken B, Hossfeld DK, Kisro J, Metzner B, Berdel WE, Diehl V, Engert A. Cologne high-dose sequential chemotherapy in relapsed and 
refractory Hodgkin lymphoma: results of a large multicenter study of the German Hodgkin Lymphoma Study Group (GHSG). Ann Oncol. 2005; 16:116-23.

3. Bartlett NL, Niedzwiecki D, Johnson JL, Friedberg JW, Johnson KB, van Besien K, Zelenetz AD, Cheson BD, Canellos GP, and Cancer Leukemia Group B. Gemcitabine, vinorelbine, and pegylated liposomal doxorubicin (GVD), a salvage regimen in relapsed Hodgkin's lymphoma: CALGB 59804. Ann Oncol. 2007; 18:1071-79.

4. Kuruvilla J, Nagy T, Pintilie M, Tsang R, Keating A, Crump M. Similar response rates and superior early progression-free survival with gemcitabine, dexamethasone, and cisplatin salvage therapy compared with carmustine, etoposide, cytarabine, and melphalan salvage therapy prior to autologous stem cell transplantation for recurrent or refractory Hodgkin lymphoma. Cancer. 2006; 106:353-60.

5. Borchmann S, von Tresckow B. Novel agents in classical Hodgkin lymphoma. Leuk Lymphoma. 2017; 58:2275-86.

6. Glimelius I, Diepstra A. Novel treatment concepts in Hodgkin lymphoma. J Intern Med. 2017; 281:247-60.

7. Moskowitz AJ, Perales MA, Kewalramani T, Yahalom J, Castro-Malaspina H, Zhang Z, Vanak J, Zelenetz AD, Moskowitz CH. Outcomes for patients who fail high dose chemoradiotherapy and autologous stem cell rescue for relapsed and primary refractory Hodgkin lymphoma. Br J Haematol. 2009; 146:158-63.

8. Kaloyannidis P, Voutiadou G, Baltadakis I, Tsirigotis P, Spyridonidis A, Repousis P, Balta A, Tsimberis S, Karakasis D, Sakellari I, Dervenoulas I, Harhalakis N, Anagnostopoulos A. Outcomes of Hodgkin's lymphoma patients with relapse or progression following autologous hematopoietic cell transplantation. Biol Blood Marrow Transplant. 2012; 18:451-57.

9. Küppers R. The biology of Hodgkin's lymphoma. Nat Rev Cancer. 2009; 9:15-27.

10. Vassilakopoulos TP, Angelopoulou MK, Siakantaris MP, Kontopidou FN, Dimopoulou MN, Boutsis DE, Anargyrou K, Kokoris SI, Giannakakis A, Karkantaris C, Kyrtsonis MC, Tsaftaridis P, Rombos J, et al. Hodgkin's lymphoma in first relapse following chemotherapy or combined modality therapy: analysis of outcome and prognostic factors after conventional salvage therapy. Eur J Haematol. 2002; 68:289-98.

11. Younes A, Gopal AK, Smith SE, Ansell SM, Rosenblatt JD, Savage KJ, Ramchandren R, Bartlett NL, Cheson BD, de Vos S, Forero-Torres A, Moskowitz CH, Connors JM, et al. Results of a pivotal phase II study of brentuximab vedotin for patients with relapsed or refractory Hodgkin's lymphoma. J Clin Oncol. 2012; 30:2183-89.

12. Rothe A, Sasse S, Goergen H, Eichenauer DA, Lohri A, Jäger U, Bangard C, Böll B, von Bergwelt Baildon M, Theurich S, Borchmann P, Engert A. Brentuximab vedotin for relapsed or refractory $\mathrm{CD} 30$ + hematologic malignancies: the German Hodgkin Study Group experience. Blood. 2012; 120:1470-72.
13. Zinzani PL, Sasse S, Radford J, Shonukan O, Bonthapally V. Experience of brentuximab vedotin in relapsed/ refractory Hodgkin lymphoma and relapsed/refractory systemic anaplastic large-cell lymphoma in the Named Patient Program: review of the literature. Crit Rev Oncol Hematol. 2015; 95:359-69.

14. Zinzani PL, Viviani S, Anastasia A, Vitolo U, Luminari S, Zaja F, Corradini P, Spina M, Brusamolino E, Gianni AM, Santoro A, Botto B, Derenzini E, et al. Brentuximab vedotin in relapsed/refractory Hodgkin's lymphoma: the Italian experience and results of its use in daily clinical practice outside clinical trials. Haematologica. 2013; 98:1232-36.

15. Gibb A, Jones C, Bloor A, Kulkarni S, Illidge T, Linton $\mathrm{K}$, Radford J. Brentuximab vedotin in refractory CD30+ lymphomas: a bridge to allogeneic transplantation in approximately one quarter of patients treated on a Named Patient Programme at a single UK center. Haematologica. 2013; 98:611-14.

16. Yang QM, Hong JY, Ko YH, Lin SY, Au WY, Choi MK, Park S, Kim SJ, Kim WS. Brentuximab vedotin for relapsed or refractory CD30+ Hodgkin lymphoma: a multicenter analysis from Asia. Onco Targets Ther. 2014; 7:1717-22.

17. Salihoglu A, Elverdi T, Karadogan I, Paydas S, Ozdemir E, Erdem G, Karadurmus N, Akyol G, Kaynar L, Yegin Z, Sucak G, Ozkocaman V, Topcuoglu P, et al. Brentuximab vedotin for relapsed or refractory Hodgkin lymphoma: experience in Turkey. Ann Hematol. 2015; 94:415-20.

18. Perrot A, Monjanel H, Bouabdallah R, Quittet P, Sarkozy C, Bernard M, Stamatoullas A, Borel C, Bouabdallah K, Nicolas-Virelizier E, Fournier M, Morschhauser F, Brice P, and Lymphoma Study Association (LYSA). Impact of postbrentuximab vedotin consolidation on relapsed/refractory CD30+ Hodgkin lymphomas: a large retrospective study on 240 patients enrolled in the French Named-Patient Program. Haematologica. 2016; 101:466-73.

19. Chen R, Palmer JM, Thomas SH, Tsai NC, Farol L, Nademanee A, Forman SJ, Gopal AK. Brentuximab vedotin enables successful reduced-intensity allogeneic hematopoietic cell transplantation in patients with relapsed or refractory Hodgkin lymphoma. Blood. 2012; 119:637981.

20. Illidge T, Bouabdallah R, Chen R, Gopal AK, Moskowitz $\mathrm{CH}$, Ramchandren R, Shustov AR, Tilly H, Trippett TM, Gibb A, Grove LE, Advani R. Allogeneic transplant following brentuximab vedotin in patients with relapsed or refractory Hodgkin lymphoma and systemic anaplastic large cell lymphoma. Leuk Lymphoma. 2015; 56:703-10.

21. Gopal AK, Chen R, Smith SE, Ansell SM, Rosenblatt JD, Savage KJ, Connors JM, Engert A, Larsen EK, Chi X, Sievers EL, Younes A. Durable remissions in a pivotal phase 2 study of brentuximab vedotin in relapsed or refractory Hodgkin lymphoma. Blood. 2015; 125:1236-43.

22. Chen R, Gopal AK, Smith SE, Ansell SM, Rosenblatt JD, Savage KJ, Connors JM, Engert A, Larsen EK, Huebner D, Fong A, Younes A. Five-year survival and durability 
results of brentuximab vedotin in patients with relapsed or refractory Hodgkin lymphoma. Blood. 2016; 128:1562-66.

23. Gandolfi L, Pellegrini C, Casadei B, Stefoni V, Broccoli A, Tonialini L, Morigi A, Argnani L, Zinzani PL. LongTerm Responders After Brentuximab Vedotin: SingleCenter Experience on Relapsed and Refractory Hodgkin Lymphoma and Anaplastic Large Cell Lymphoma Patients. Oncologist. 2016; 21:1436-41.

24. Gopal AK, Bartlett NL, Forero-Torres A, Younes A, Chen R, Friedberg JW, Matous JV, Shustov AR, Smith SE, Zain J, O'Meara MM, Fanale MA. Brentuximab vedotin in patients aged 60 years or older with relapsed or refractory CD30-positive lymphomas: a retrospective evaluation of safety and efficacy. Leuk Lymphoma. 2014; 55:2328-34.

25. Forero-Torres A, Holkova B, Goldschmidt J, Chen R, Olsen G, Boccia RV, Bordoni RE, Friedberg JW, Sharman JP, Palanca-Wessels MC, Wang Y, Yasenchak CA. Phase 2 study of frontline brentuximab vedotin monotherapy in Hodgkin lymphoma patients aged 60 years and older. Blood. 2015; 126:2798-804.

26. Chen R, Palmer JM, Martin P, Tsai N, Kim Y, Chen BT, Popplewell L, Siddiqi T, Thomas SH, Mott M, Sahebi F, Armenian S, Leonard J, et al. Results of a Multicenter Phase II Trial of Brentuximab Vedotin as Second-Line Therapy before Autologous Transplantation in Relapsed/Refractory Hodgkin Lymphoma. Biol Blood Marrow Transplant. 2015; 21:2136-40.
27. Chen R, Palmer J, Martin P, Armenian S, Tsai N, Mott M, Sahebi F, Cai J, Siddiqi T, Popplewell LL, Leonard JP, Nademanee AP, Forman SJ, et al. Post Transplant Outcome of a Multicenter Phase II Study of Brentuximab Vedotin as First Line Salvage Therapy in Relapsed/Refractory HL Prior to AHCT. Clin Adv Hematol Oncol. 2016 (Suppl 1); 14:7-8.

28. Argnani L, Zinzani PL. Reporting real-life experience with drugs in lymphoma patients. Hematol Oncol. 2016 Mar 21. doi: 10.1002/hon.2284. [Epub ahead of print]

29. Cheson BD, Pfistner B, Juweid ME, Gascoyne RD, Specht L, Horning SJ, Coiffier B, Fisher RI, Hagenbeek A, Zucca E, Rosen ST, Stroobants S, Lister TA, et al, and International Harmonization Project on Lymphoma. Revised response criteria for malignant lymphoma. J Clin Oncol. 2007; 25:579-86. 